\title{
Online Medical Education in India - Different Challenges and Probable Solutions in the Age of COVID-19
} This article was published in the following Dove Press journal:
Advances in Medical Education and Practice

Introduction: During the COVID-19 pandemic, most educational institutions have opted for online education rather than traditional modes of education to protect their employees and students. Online education has been gaining momentum in almost all countries around the world. This coincides with the recently introduced competency-based medical education in India which has embraced online education. This poses a new challenge for the institutions involved, the instructors or teachers, and the students since they must adapt quickly to the new mode of learning. Online education requires teachers to improve their competency in three major areas; pedagogy, technology, and content knowledge. Some of the challenges include; lack of technological skill, poor time management and lack of infrastructure. As technology rapidly advances, health care education systems must also advance in tandem. To implement the new competency-based system and online education, the institutions and the individuals must realize the importance of online education, identify the barriers and quickly work on solutions for success.

Methods: This review was conducted based on various research papers on the topic of online medical education, the challenges faced by faculty members, and the opinion of students on this dilemma. Search terms included online medical education, COVID19, competency-based medical education.

Conclusion: This review identified various challenges posed by online education on the current medical curriculum, faced by both faculty members and students, especially under the light of the Competency-Based Undergraduate Curriculum for Indian Graduates. Different solutions were proposed to overcome these challenges.

Keywords: online medical education, COVID-19, competency-based medical education

\section{Introduction}

The World Health Organization (WHO) alerted the world of several atypical pneumonia cases in Wuhan, China, a city populated by over 11 million people, on December 31, 2019. The cases had no apparent cause prompting the organization to start investigations. By January 3rd, there were a total of 44 documented cases. The source was traced to a seafood market in Wuhan but the cause was still a mystery. By January 7th, a new strain of coronavirus was identified and named; SARS-COV-2 (severe acute respiratory syndrome coronavirus 2). By January 31st, there were over 9000 cases reported globally. The rate at which the new virus was spreading started to cause panic, and the WHO declared a "global emergency". By March, more than 11 countries had been affected by the virus, and the pandemic
Correspondence: Nirav Nimavat Department of Community Medicine, SBKS MIRC, Sumandeep Vidyapeeth Deemed to Be University, Piparia

Vadodara, 391760, Gujarat, India

Tel +9l 8866271087

Email nkniraj1529@gmail.com
Advances in Medical Education and Practice 2021:12 237-243 
status was declared. ${ }^{1}$ Many countries subsequently imposed containment measures including nation-wide shutdowns. These included schools, universities, and medical schools.

Contact with patients is essential in educating medical students and they cannot only rely on books for medical knowledge and competency. ${ }^{2}$ Medical students face challenges that set them apart from most college students, since they can get infected during a clinical session with a patient who is SARS-COV-2 positive, or they can serve as a vector, thus harming the patient and their colleagues including professors and doctors. Almost all students returned to their hometowns because of the lockdown, even medical conferences were postponed or cancelled altogether. Medical students and teachers explored new ways of learning/teaching and this led them to online learning. Online learning assumes various forms such as online classes, live web simulations, webcasting, and online chat rooms. ${ }^{3}$

India is keen to implement the new competency-based education system. The competency-based medical education (CMBE) favors skill development and focuses on training professionals to deliver Indian medical graduates that are globally competitive and can meet society's increasing health needs. This means that Indian medical students need training in clinical settings, practice with patients and make regular visits to out-patient clinics. ${ }^{4,5}$

The competency-based system aims to implement these core ideas into the Indian medical education system $^{4,5}$ (Figure 1). The CMBE curriculum goals can be divided into; national goals, institutional goals and goals for the learner. The goals aim to create a medical health professional who understands and provides preventive, promotive, curative, palliative, and holistic care with compassion and are committed to excellence. They should also be ethical, responsive, and accountable to patients, community, and profession. ${ }^{4,5}$

Thus, the new CBME curriculum encourages both traditional learning methods for the clinical exposure and the best available evidence online for keeping up with the latest medical updates and to strengthen the student's research abilities. The effects of COVID-19 were detrimental to this process. After spending a lot of resources and time to set up the curriculum for students admitted in 2019 , the whole process had been disrupted by the pandemic. Students admitted in 2019 had a shortage of clinical knowledge and practical skills due to the disruption of clinical rotations and live contact with real patients and laboratory practical. ${ }^{6}$ In many countries, medical education is conducted through the classroom and practical
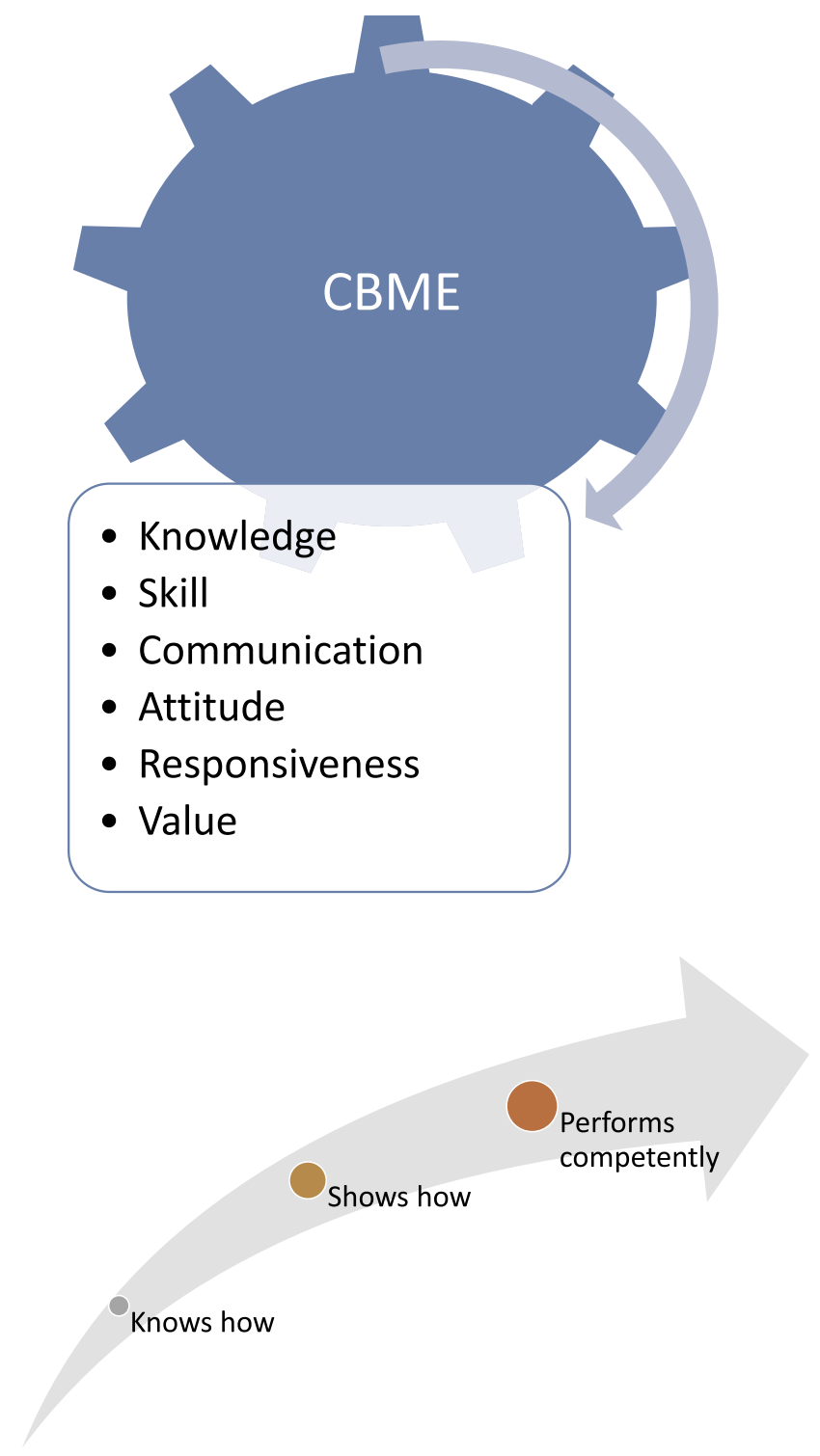

Figure I Pillars of competency-based medical education.

sessions. The usage of online teaching tools (Table 1) was very limited throughout the regular courses run in the medical schools. Although many distance learning courses were offered through online platforms, all the faculties of medical schools and students were not habituated to using these tools during the progression of daily teaching and learning.

The Indian Medical Association argues that this will not only harm medical education and medical students but also the society, since, future doctors might lack the skills gained during clinical rotations. Thus, medical professors across the country have to work hard to maximize the benefit of online education and to minimize the damage caused by the disruption in clinical rotations. Though the majority of the developed 
Table I List of Online Tools for Online Teaching and Learning

\begin{tabular}{|l|l|l|}
\hline Purpose & Tool & Link \\
\hline $\begin{array}{l}\text { Discussion } \\
\text { forum }\end{array}$ & Blackboard & https://www.blackboard.com/ \\
\cline { 2 - 3 } & Moodle & https://moodle.org \\
\cline { 2 - 3 } $\begin{array}{l}\text { Online } \\
\text { teaching }\end{array}$ & Schoology & $\underline{\text { https://www.schoology.com/ }}$ \\
\cline { 2 - 3 } & Webex & https://www.webex.com/ \\
\cline { 2 - 3 } & Zoom & https://zoom.us/ \\
\cline { 2 - 3 } & Google meet & $\underline{\text { https://www.skype.com/ }}$ \\
\cline { 2 - 3 } & https://gsuite.google.com/pro \\
\cline { 2 - 3 } & Team viewer & https://www.teamviewer.com// \\
\hline
\end{tabular}

countries have adequate infrastructure to deal with the increase in health care and medical education demands, the lower- and middle-income countries, have difficulties in handling these challenges during the pandemic. ${ }^{7}$ Medical schools are facing difficulties in adapting to the new online education and the technological advancements of the health care system while maintaining excellence in education. Despite all these barriers and challenges, it has been demonstrated that online learning holds certain advantages over traditional learning in content delivery and delivery of the newest evidence-based medicine. It can cross geographical barriers, thus communication with health care professionals from multiple countries can be done. Its flexibility ensures that the learner gains more control over their learning. ${ }^{8}$

\section{Methods}

An extensive search was conducted on this topic. Search databases used were PubMed, Medline, Google scholar, Wiley online Library and all the literature including original papers, perspectives, topic reviews, focused on medical tutors' experience in online education were included. The PubMed/Medline search was made using the keyword "Online Medical Education", “COVID-19”, "Competency Based Medical Education". The literature was critically examined to analyze the use of online teaching-learning impact on medical students and faculty. A detailed analysis was established after reviewing the text papers and deductions were made to fit two main themes:

1. Challenges to the medical education curriculum due to E-learning
2. Probable solutions to these challenges

\section{Major Challenges Faced and Probable Solutions}

Medical Council of India (MCI) and recently re-enacted National Medical Commission (NMC), the leading regulator of medical education in India, has recognized the importance of online education. For students and faculty members to fully utilize electronic means in learning, they must overcome the challenge posed by the fact that e-learning was not the cornerstone in medical education. In fact, it was rarely used due to the clinical nature of the curriculum.

It has been established that the barriers to medical e-learning are due to time constraints, poor technical skills, poor infrastructure, lack of institutional strategies, and a general negative attitude towards the huge shift in education methods. ${ }^{9}$ The following are the main challenges faced during online learning (Table 2).

\section{Lack of Skills}

Lack of technical skills was the first challenge identified in online teaching. Insufficient computer and/or writing skills have aggravated a general negative attitude from professors towards the new e-learning system and this negatively impacts the delivery of online learning. ${ }^{10}$ The students will not be able to develop necessary clinical skills through online education systems, which may exacerbate the burden on their mental health. ${ }^{11}$

\section{Solution, Engagement}

This is an institution's responsibility, to engage teachers in learning new technical skills, and to provide them with the necessary tools and means to improve their usage of electronic methods. This can positively affect the teacher's attitude, and reduce their resistance towards e-learning. ${ }^{10}$ For students who were not able to develop clinical skills,

Table 2 Main Challenges Faced During Online Teaching and Learning

\begin{tabular}{|l|c|}
\hline Sr. No & Challenges \\
\hline 1 & Lack of skills \\
2 & Time management \\
3 & Lack of infrastructure/resources \\
4 & Poor communication at various levels \\
5 & The negative attitude \\
6 & Student engagement \\
\hline
\end{tabular}


should be posted on a special clinical rotation schedule after a routine medical school teaching resume. So they can also acquire respective skills related to clinical work.

\section{Time Management}

Before the pandemic began, Professors were already struggling to efficiently manage time in order to deliver all the information required in the curriculum. A sudden transition from classroom learning to online teaching requires a lot of time and work from faculty and staff members. Teachers have to find time to improve their technical skills, rewrite content that was only suitable for clinical practice to fit the online delivery method, overcome technical problems and find ways to keep the students engaged in online lectures. All these make no consideration for the teacher's personal life and mental health due to this increasing amount of stress $^{10,11}$ as clinicians are also busy with COVID-19 patient management. In the same way, students may also find it difficult to manage all the online classes, particularly the duration of lecture and the gap between two lectures, scheduled as per the availability of faculty.

\section{Solution, Encouraging Effective Time Management}

This begins by developing a capacity-building program that should train all the faculties for the implementation of online learning. Training should be followed by post-implementation feedback, so that any gaps should be identified and addressed. ${ }^{12}$ The program should effectively help teachers make certain changes that may be required, such as the addition of subject matter to meet the online teaching requirements. Communication of the curriculum implementation plan should be done in advance to the students. A detailed timetable of each session along with the contact number of the faculty, study materials, and timings should be communicated to students in advance, which will help students manage their study time in a more efficient manner. ${ }^{12-14}$ COVID-19 ward staff on duty, as well as teachers, can teach online. To reduce the number of sessions per day, prerecorded sessions can be shared, which will be beneficial and stress relieving. ${ }^{15}$

\section{Lack of Infrastructure/Resources}

This is another important barrier to the success of the online education, especially in medium to low-income countries. The students from financially disadvantaged groups may not have smart devices (Laptops, Tablets and Smart Phones) to access the online teaching-learning. ${ }^{16} \mathrm{In}$ the last few years, India had made good progress in internet accessibility and affordability but a major limitation was in geographical access. This meant that some students who have returned to their home towns due to the pandemic might not have had regular access to the internet. ${ }^{10-12}$ As per the "Digital in India" report 2019, $54 \%$ of urban population and $32 \%$ of rural population, in the age group of 12 years and above had internet access. ${ }^{17}$ The systemic review on "evaluation of e-learning in medical education for low and middle income countries" also identified and highlight the lack of infrastructure/resources in medical schools of these countries. ${ }^{8}$ The recent studies from the developing countries, mainly focused on e-learning in medical education during the COVID-19 pandemic, identified limited availability of digital resources for students, frontline healthcare professional have limited capacity to develop online teaching materials. ${ }^{18-20}$ Poor internet access has been also addressed in the recent study from a developing country. ${ }^{21}$

\section{Solution}

Infrastructure in the context of mobile and internet connectivity is the responsibility of the government/private institutions. The Indian government did well in response to this context. There are still some areas where internet access is a problem and these issues must be prioritized in the future economic, digitalization and education policies. $^{22}$

\section{Poor Communication at Various Levels}

The implementation of online learning to suit the competency-based curriculum is a process involving the institution as much as the teachers and students. The lack of support from the institution and the lack of inter-departmental communication might cause problems. Two departments might schedule lectures at the same time, for example, or they might schedule lectures without allowing the students a chance to rest and focus. This may lead to students lacking concentration and understanding of medical education as a whole. ${ }^{10-12}$

\section{Solution, Collaboration}

Research has shown that one of the most important factors for the success of the e-learning module is establishing an environment where all department heads can communicate easily and efficiently. This requires an institutional strategy to ensure that all departments can co-ordinate with each other, under a formal mechanism without a problem. Establishing a team can help overcome the communication barrier; ${ }^{10}$ 
The first step for proper delivery of the competencybased curriculum is to establish a team in each medical school, comprised of those who are associated with curriculum implementation. The team should analyze the available infrastructure, tools required and training of all faculty members. All the necessary tools (software) need to be purchased at the earliest opportunity. The team should consist of a Team Leader - preferably the head of the institute, curriculum development, and implementation director, other supporting staff from the information technology department, learning resource system, and student representatives. ${ }^{23,24}$

\section{The Negative Attitude}

Students and teachers had a negative attitude towards new technologies. Teachers had indicated that learning new techniques was challenging for them, especially when facing technical issues. This caused a general feeling of inadequacy. ${ }^{10,13,14}$

The study conducted in Pakistan by Abbasi et al reports the negative attitude towards e-learning and preferred face-to-face learning because of poor internet access and stability. ${ }^{21}$

\section{Solution, Culture}

Creating a general environment of positivity and hope for the educators and students can help solve this problem. The idea that "it's never too late to learn" should be reinforced throughout the educational system. The change in norms and attitudes should be fostered on both the institutional level and the individual level to help in the success of the new online education module. ${ }^{10,12}$

\section{Student Engagement}

Many students faced the problem of staying focused while in an online classroom, due to the distractions around them whether from family or surroundings. When there is a lack of skill, as discussed above in the first challenge, online communication between teachers and students can be impeded. This makes it harder for students to interact with their teachers and thus lose focus, the excitement that comes from clinical practice in the medical field is also diminished. Motivating students through regular class assessments is also difficult. ${ }^{10,13}$

\section{Solution, Maintain Interest}

The curriculum should be delivered in synchronous and asynchronous mode. The synchronous mode allows learners to interact with the teacher and other classmates during a discussion, while the asynchronous mode allows students to take part in the discussion over the internet. The synchronous mode allows instant interaction and feedback, while the other allows time to think through issues. E-lectures, virtual patient, e-labs will primarily serve as synchronous mode options. Other options like chat rooms and discussion forums can be used for better engagement and interaction. ${ }^{25}$ To increase participation and engagement, the following should be considered during an online lecture; keeping marks for each post/question, minimum and effective post. The creative and constructive post will increase the student's engagement and participation. Mini assignments after each lecture will increase the feedback mechanism. Certain video game tools are available online for better understanding and engagement of students for learning. These tools enhance their thought process; planning, prompt response, problem-solving, and analysis skill. Virtual patients will allow open-ended questions and enable students to interpret data and make decisions accordingly. ${ }^{26}$ Students will make a diagnosis and prepare a treatment regimen accordingly. There are certain widely used social media tools like WhatsApp, YouTube and Facebook, which have good prospects for medical education.

During online learning, it has been found that recorded video will be more powerful than directly switching to live online classes. During this time, continuing mentoring and self-directed learning will be more effective. As online learning is more independent, proper instructions regarding assignment must be provided to motivate the students. Multiple choice questions, mini-quizzes are also important strategies for effective online learning. ${ }^{27}$ Transcript of the slide, on-screen caption, limiting the texts in the slide, will also motivate the students for better engagement.

\section{Assessment of the Students}

The assessment of the students done in the competencybased curriculum (CBME) focuses on the student's skill development, ie what the student can perform. Multiple methods can be used to assess the cognitive and behavioral competencies. $^{28}$

In routine assessment, cognitive competency assessment performed through case-vignette-based multiple choice question (MCQ), short answer questions (SAQs) and long answer questions (LQAs). Allotment of long case/short case and viva for the same used for assessing the ability to diagnose and interpret the clinical or practical problem. For assessment of clinical and practical skills, methods used are objective structured clinical/practical examination (OSCE/ $\mathrm{PE})$ and direct observation of procedural skills (DOPS). ${ }^{29}$ 
Student assessment in the online learning process should be evaluated mainly in the form of "formative learning" rather than "summative learning". There are many online assessment tools like Quizlet Live, Kahoot and Nearpod. Google quizzes through Google forums are as effective as other tools. There are certain tools for summative assessment that assess the knowledge domain of the students through an open-book exam, essay questions, and assignments. ${ }^{30}$ Assessment of the psychomotor domain is the most challenging in online learning. Virtual objective structured clinical examinations and a virtual patient can be used for clinical reasoning assessment.

So, in summary, despite all the barriers to online medical education and challenges for the implementation of the CBME curriculum, solutions exist. E-learning might even have some advantages over traditional learning regarding some aspects. Here is a brief comparison ${ }^{31}$ (Figure 2).

\section{The Scope of Improvement}

After each session, student feedback and faculty feedback are both important for improving the ongoing online teaching sessions. This feedback can be collected by using online questionnaires. These questions can include topics like the timing of the session, tools used for the teaching, challenges faced, and how to overcome these challenges. Timely feedback from the students and faculty and analysis of the feedback will improve the effectiveness of online teaching and learning.

This review summarized key points in the challenges that face educators in the new E-learning educational system while offering solutions to solve these challenges.

The shift from clinical-based teaching to online teaching has posed new challenges for the medical education system in India, but these challenges can be overcome by the collaboration of the institution, faculty members, and students.

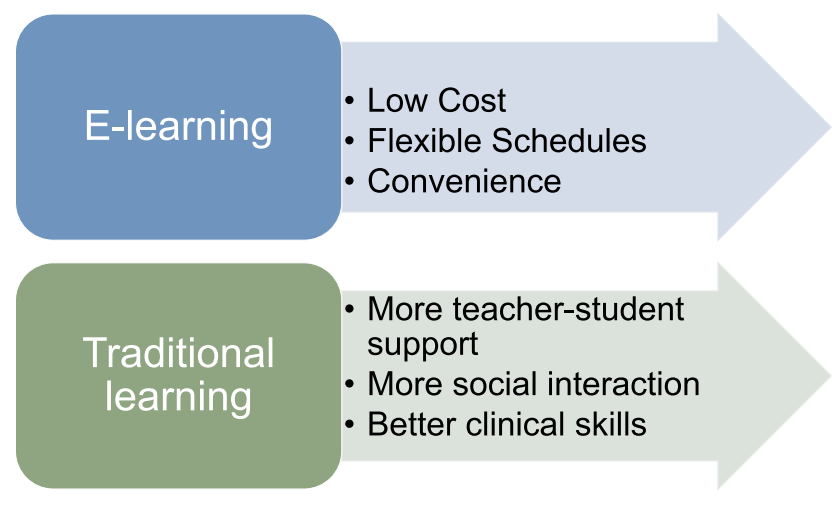

Figure 2 Advantage of e-learning over traditional system.
Despite the barriers that online education imposes on the CBME curriculum, e-learning might have certain advantages over traditional education methods. Institutions should encourage their educators to try to accommodate new skills and co-operate to maximize the efficiency of online content delivery to the students. Educators can encourage their students to actively participate in the online learning process and try to gain as much information as they can. Adaptation to this new system is no longer a luxury as Covid-19 effects on the medical education system and the nation's health care system will most likely last for years to come.

\section{Conclusion}

This sudden transition of medical education from the classroom to online has unique challenges for the faculty as well as the student. Due to the pressure to deliver the same content on different platforms than the regular one, educators are used to, timely preparation and delivery of content through an online platform can be problematic. Barriers such as lack of skill and infrastructure, poor time management, and communication can be overcome with solutions detailed in this article. The Indian medical education system is currently facing many threats. Institutions, educators, and students can save the system from collapsing by incorporating CMBE ideals into the e-learning system. The need for a properly working health care system is vital, especially after the pandemic. The graduation of highly competent Indian health care professionals is achievable if all concerned parties start co-operating. Despite all the hiccups, online medical education is gaining momentum in India due to the advantages of online education and the push by stakeholders to sustain it through the pandemic.

\section{Suggestions for Future Studies}

As during pandemic online medical education become necessity for teaching-learning activities, the developing countries should address these challenges, and relevant epidemiological studies (cross sectional, case control, cohort, randomized control trial) and qualitative studies can be planned to get the detailed view.

\section{Abbreviations}

COVID-19, coronavirus disease-2019; SARS COV-2, severe acute respiratory syndrome coronavirus 2; WHO, World Health Organization; CBME, competency-based medical education; MCI, Medical Council of India; NMC, National 
Medical Commission; OSCE/PE, objective structured clinical/ practical examination.

\section{Disclosure}

The authors report no conflicts of interest in this work.

\section{References}

1. CDC COVID Data Tracker.Available from: https://www.cdc.gov/cor onavirus/2019-ncov/index.html. Accessed February 17, 2021.

2. Byrnes YM, Civantos AM, Go BC, McWilliams TL, Rajasekaran K. Effect of the COVID-19 pandemic on medical student career perceptions: a national survey study. Med Educ Online. 2020;25 (1):1798088. doi:10.1080/10872981.2020.1798088

3. Ish P, Sakthivel P, Gupta N, Malhotra N, Rajeshwari M. E-learning of medical residents during COVID-19: perspective from a developing nation. Postgrad Med J. 2020;postgradmedj-2020-139022. doi:10.1136/postgradmedj-2020-139022

4. India MC. Competency Based Undergraduate Curriculum for the Indian Medical Graduate. 2018.

5. Modi JN, Gupta P, Singh T. Competency-based medical education, entrustment and assessment. Indian Pediatr. 2015;52(5):413-420. doi:10.1007/s13312-015-0647-5

6. Rose S. Medical student education in the time of COVID-19. JAMA. 2020;323(21):2131-2132. doi:10.1001/jama.2020.5227

7. Solanki A, Kashyap S. Medical education in India: current challenges and the way forward. Med Teach. 2014;36(12):1027-1031. doi:10.3109/0142159X.2014.927574

8. Barteit S, Guzek D, Jahn A, Bärnighausen T, Jorge MM, Neuhann F. Evaluation of e-learning for medical education in low- and middle-income countries: a systematic review. Comput Educ. 2020;145:103726. doi:10.1016/j.compedu.2019.103726

9. Saiyad S, Virk A, Mahajan R, Singh T. Online teaching in medical training: establishing good online teaching practices from cumulative experience. Int J Appl Basic Med Res. 2020;10(3):149-155. doi:10.4103/ijabmr.IJABMR_358_20

10. O'Doherty D, Dromey M, Lougheed J, Hannigan A, Last J, McGrath D. Barriers and solutions to online learning in medical education - an integrative review. BMC Med Educ. 2018;18(1):130. doi:10.1186/s12909-018-1240-0

11. Costello E, Corcoran M, Barnett J, et al. Information and communication technology to facilitate learning for students in the health professions: current uses, gaps and future directions. Online Learn. 2014;18(4). doi:10.24059/olj.v18i4.512

12. Dyrbye L, Cumyn A, Day H, Heflin M. A qualitative study of physicians' experiences with online learning in a masters degree program: benefits, challenges, and proposed solutions. Med Teach. 2009;31(2):e40-e46. doi:10.1080/01421590802366129

13. Del Rio C, Malani PN. 2019 Novel Coronavirus - important information for clinicians. JAMA. 2020;323(11):1039. doi:10.1001/jama.2020.1490

14. Hollander JE, Carr BG. Virtually perfect? Telemedicine for Covid-19. N Engl J Med. 2020;382(18):1679-1681. doi:10.1056/ NEJMp2003539

Advances in Medical Education and Practice

\section{Publish your work in this journal}

Advances in Medical Education and Practice is an international, peerreviewed, open access journal that aims to present and publish research on Medical Education covering medical, dental, nursing and allied health care professional education. The journal covers undergraduate education, postgraduate training and continuing medical education
15. Taha MH, Abdalla ME, Wadi M, Khalafalla H. Curriculum delivery in Medical Education during an emergency: a guide based on the responses to the COVID-19 pandemic. MedEdPublish. 2020;9(1). doi:10.15694/mep.2020.000069.1

16. Universities tackle the impact of COVID-19 on disadvantaged students. Available from: https://en.unesco.org/news/universities-tackle-impactcovid-19-disadvantaged-students. Accessed January 15, 2021.

17. Nielsen. Digital in India:2019-Round 2 Report. 2019.

18. Aghakhani K, Shalbafan M. What COVID-19 outbreak in Iran teaches us about virtual medical education. Med Educ Online. 2020;25 (1):1770567. doi:10.1080/10872981.2020.1770567

19. Sethi BA, Sethi A, Ali S, Aamir HS. Impact of Coronavirus disease (COVID-19) pandemic on health professionals. Pak J Med Sci. 2020;36(COVID19-S4). doi:10.12669/pjms.36.COVID19-S4.2779

20. Sahi PK, Mishra D, Singh T. Medical education amid the COVID-19 Pandemic. Indian Pediatr. 2020;57(7):652-657. doi:10.1007/s13312020-1894-7

21. Abbasi S, Ayoob T, Malik A, Memon SI. Perceptions of students regarding E-learning during Covid-19 at a private medical college. Pak J Med Sci. 2020;36(COVID19-S4). doi:10.12669/pjms.36. COVID19-S4.2766

22. World Economic Forum. How COVID-19 deepens the digital education divide in India. Available from: https://www.weforum.org/ agenda/2020/10/how-covid-19-deepens-the-digital-education-dividein-india/. Accessed January 15, 2021.

23. Moran J, Briscoe G, Peglow S. Current technology in advancing medical education: perspectives for learning and providing care. Acad Psychiatry. 2018;42(6):796-799. doi:10.1007/s40596-018-0946-y

24. Gagne RM, Wager WW, Golas KC, Keller JM, Russell JD. Principles of instructional design, 5th edition. Perform Improv. 2005;44 (2):44-46. doi:10.1002/pfi.4140440211

25. Goh P-S, Sandars J. A vision of the use of technology in medical education after the COVID-19 pandemic. MedEdPublish. 2020;9(1). doi: $10.15694 / \mathrm{mep} .2020 .000049 .1$

26. Imperial College London. COVID-19 response: edTech expertise strengthening remote learning transition | Imperial News. Available from: https://www.imperial.ac.uk/news/196253/covid-19-responseedtech-expertise-strengtheningremote/. Accessed November 9, 2020.

27. Skochelak SE, Stack SJ. Creating the medical schools of the future. Acad Med. 2017;92(1):16-19. doi:10.1097/ACM.0000000000001160

28. Badyal DK, Singh S, Singh T. Construct validity and predictive utility of internal assessment in undergraduate medical education. Natl Med J India. 2020;30(3):151-154.

29. Badyal DK, Sharma M. Internal assessment in new MBBS curriculum: methods and logistics. Int J Appl Basic Med Res. 2020;10 (2):68-75. doi:10.4103/ijabmr.IJABMR_70_20

30. Barzansky B LCME update on medical students, patients, and COVID-19: approaches to the clinical curriculum; 2020. Available from: www.lcme.org. Accessed November 9, 2020.

31. Aggarwal R, Gupte N, Kass N, et al. A comparison of online versus on-site training in health research methodology: a randomized study. BMC Med Educ. 2011;11(1):37. doi:10.1186/1472-6920-11-37 including emerging trends and innovative models linking education, research, and health care services. The manuscript management system is completely online and includes a very quick and fair peer-review system. Visit http://www.dovepress.com/testimonials.php to read real quotes from published authors. 